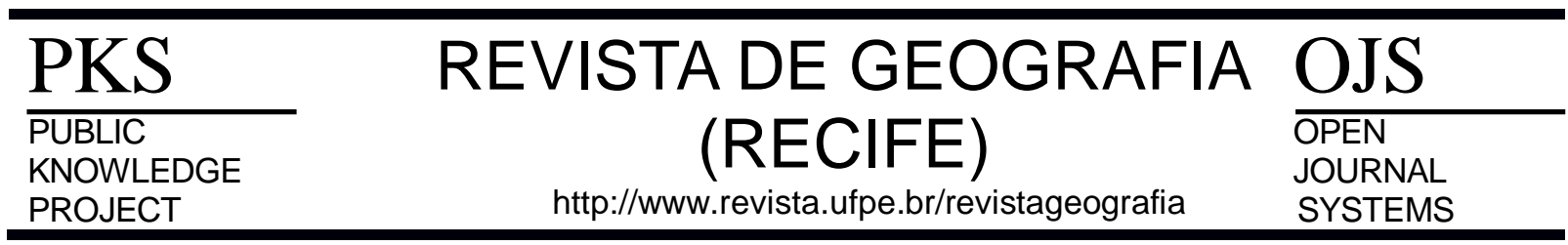

\section{ANÁLISE DA HIERARQUIA URBANA NA MESORREGIÃO DO TRIÂNGULO MINEIRO E ALTO PARANAÍBA}

\author{
João Benvindo do Amaral ${ }^{1}$, Ana Márcia Moreira Alvim²
}

${ }^{1}$ Mestre em Geografia pelo Programa de Pós-graduação em Geografia da Universidade Católica de Minas Gerais.. E-mail: joaobgeo@gmail.com

${ }^{2}$ Professora Adjunta IV do Programa de Pós-graduação em Geografia da Universidade católica de Minas Gerais. E-mail: ammalvim@gmail.com

Artigo recebido em 14/04/2017 e aceito em 19/01/2018.

\begin{abstract}
RESUMO
Atualmente, dentro do planejamento regional é fundamental o estudo da hierarquia urbana de uma região, para assim, subsidiar os agentes políticos sobre o desenvolvimento regional. Dessa forma, essa pesquisa tem como objetivo central, analisar, a Hierarquia Urbana, na Mesorregião do Triângulo Mineiro e Alto Paranaíba MRTMAP, nos anos 2000 e 2010, mesorregião essa que têm 66 municípios. A justificativa desse trabalho se baseia na premissa de que analisar a hierarquia urbana de uma região é uma etapa necessária para subsidiar ações do setor público, na busca de um equilíbrio regional entre seus municípios. Metodologicamente, a pesquisa se fundamentou na Teoria dos Lugares Centrais de Christaller, na técnica de Análise de Componentes Principais e ainda propôs uma nova hierarquia urbana para a MRTMAP. A partir dos resultados foi possível verificar que Uberlândia é o Lugar Central da MRTMAP e que a Porção Leste da mesorregião é mais dinâmica que a Porção Oeste, a qual necessita de um olhar mais apurado sobre ela.

Palavras-chave: Hierarquia Urbana; Análise de Componentes Principais; Teoria dos Lugares Centrais e Mesorregião do Triângulo Mineiro e Alto Paranaíba.
\end{abstract}

\section{ANALYSIS OF URBAN HIERARCHY OF THE MESORREGIÃO OF THE TRIÂNGULO MINEIRO E ALTO PARANAÍBA}

\begin{abstract}
Currently, within the regional planning is essential the study of the urban hierarchy of a region, to subsidize the political agents on the regional development. Thus, this research has as its central objective, to analyze, the Urban Hierarchy, in the Mesoregion of the Triângulo Mineiro and Alto Paranaíba - MRTMAP, in the years 2000 and 2010, mesoregion that have 66 municípios. The justification of this work is based on the premise that analyzing the urban hierarchy of a region is a necessary step to subsidize actions of the public sector in the search for a regional balance between its municípios. Methodologically the research based on Christaller's Theory of Central Places, in the technique of Analysis of Principal Components and proposed a new urban hierarchy for MRTMAP. From the results, it was possible to verify that Uberlândia is the Central Place of MRTMAP and that the Eastern Portion of the mesorregião is more dynamic than the West Portion, in which it needs a closer look at it.

Keywords: Urban Hierarchy; Principal Component Analysis; Theory of Central Places and Mesorregião of the Triângulo Mineiro and Alto Paranaíba.
\end{abstract}




\section{INTRODUÇÃO}

Ao analisarmos e definirmos a hierarquia urbana de uma região, isso se torna um subsídio importante para os agentes políticos, uma vez que, com essas análises esses podem verificar, qual ou quais unidades espaciais, no caso municípios, devem ser privilegiados quanto ao investimento público. Nesse sentido, os municípios com menor participação na hierarquia urbana devem ter maior atenção, no que tange a distribuição dos recursos públicos, todavia é necessário identificá-los. Dessa forma, a hierarquia pode ser verificada de uma gama variada de formas, por exemplo, pela disponibilidade de bens e serviços, ditos centrais, como afirma Christaller (1966), pela sua população total, ou pelo seu nível socioeconômico. Esse último obtido, por meio de variáveis quantitativas, como o desenvolvimento humano e o produto interno bruto das cidades, com a aplicação de métodos quantitativos, em particular os que representam as análises multivariadas.

O presente trabalho é pautado no método dedutivo, e para a compreensão do caminho percorrido para sua realização, os aspectos metodológicos foram organizados em três etapas: a primeira é pautada em um referencial teórico a cerca do conceito de hierarquia urbana e também sobre a teoria de Christaller; a segunda é referente aos dados coletados, bem como suas fontes; e a terceira o tratamento desses dados.

A primeira parte é dedicada a uma análise bibliográfica, tendo como premissa a busca por uma definição do conceito de hierarquia urbana. Em seguida procurou-se analisar os aspectos teóricos relacionados à Teoria dos Lugares Centrais, proposta por Christaller em 1933.

Em um segundo momentos, para analisar a Hierarquia Urbana entre os municípios da MRTMAP foram coletadas 12 variáveis. Os dados foram utilizados na aplicação da técnica de análise multivariada denominada de Análise de Componentes Principais - ACP. Essa técnica permitiu a construção de um índice que abarcou as dimensões populacionais, econômicas, sociais, e também como base para as análises pautadas na Teoria dos Lugares Centrais de Christaller (1966), e com isso formular uma hierarquia urbana coerente para a MRTMAP.

Desse modo, essa pesquisa tem como objetivo central, analisar a Hierarquia Urbana, na Mesorregião do Triângulo Mineiro e Alto Paranaíba, nos anos 2000 e 2010 e assim verificar quais dos 66 municípios da mesorregião devem obter maior atenção dos agentes públicos, no que se refere aos investimos econômicos e sociais. Para atingir esse objetivo, 
foram definidos também três objetivos específicos: analisar uma bibliografia referente à Hierarquia Urbana; hierarquizar os municípios da mesorregião, de acordo com Christaller (1966), se valendo de uma técnica de análise multivariada, a Análise de Componentes Principais - ACP; e propor uma nova análise a partir da união entre a teoria de Christaller e a aplicação da Análise de Componentes Principais - ACP.

A justificativa desse trabalho se baseia na premissa de que analisar a hierarquia urbana de uma região é necessário para subsidiar ações do setor público, na busca de um equilíbrio entre os municípios de uma região. Além disso, outro fator é a escolha da unidade espacial de análise, no caso a Mesorregião do Triângulo Mineiro e Alto Paranaíba ${ }^{1}$, a qual é uma região de destaque no cenário estadual e nacional (Figura 1).

\section{O CONCEITO DE HIERARQUIA URBANA}

A Hierarquia Urbana pode ser definida como o nível e/ou posição que uma unidade espacial possui, em determinada rede regional. A partir disso, para Santos (1981, p. 143) a hierarquia urbana, nos países subdesenvolvidos é "flutuante e instável, e reflete a luta entre a economia nacional e estrangeira". Com base nisso, Chapoulie, citado por Santos (1981), informa que uma forma de hierarquização é pelo número de seus habitantes, por exemplo:

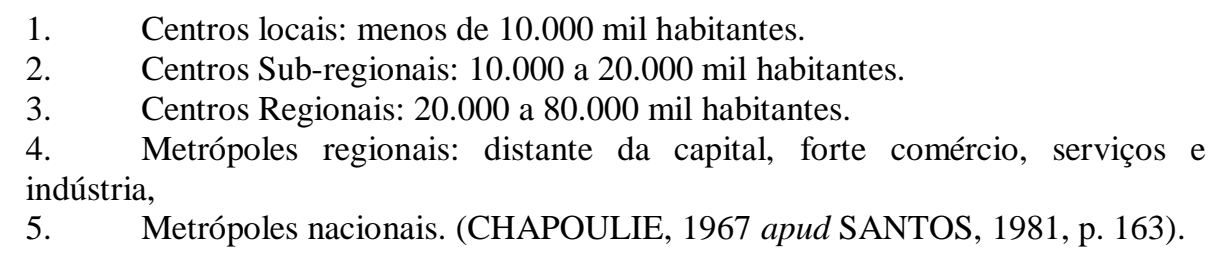

Aliando a isso, Santos (1981, p. 145) indica que "em alguns casos específicos a noção de redes hierarquizadas não se encaixa". Isso ocorre quando uma cidade polariza quase todo um país, "essas cidades são responsáveis por abrigar grande parte da população urbana desses países" (SANTOS, 1981, p. 145 e 146), o que ele denomina de "macrocefalia", e dá como exemplos, Santiago no Chile e Buenos Aires na Argentina.

Desse modo, as grandes cidades tendem a organizar as áreas próximas tanto socialmente como economicamente (JONHSON, 1974, p. 136). Contudo, será que é somente

\footnotetext{
${ }^{1}$ Para efeito de simplificação o nome da mesorregião, desse ponto em diante será substituído pela sigla MRTMAP.
} 
a grande cidade que desempenha esse papel de organizadora? No contexto exposto por Johnson (1974, p. 136), também as cidades médias podem realizar essa organização. Pois, segundo George (1983, p. 225 e 226), a cidade média assume uma posição importante na hierarquia urbana, "pelo número de seus habitantes [...], pela presença de uma máquina administrativa já mais importante, centros culturais, educação superior, teatros, comércio e indústria". Porém, esse mesmo autor evidencia que na estrutura da rede urbana, a cidade média não ocupa, geralmente, lugar significativo, do que a pequena cidade, exceto quando ela se destaca em um setor específico, por exemplo, os setores de moda, tecnologia ou agronegócio (GEORGE, 1983, p. 225 e 226).

Por outro lado, Beaujeu-Garnier (1997, p. 468) explana que as Hierarquias Urbanas pressupõem uma classificação que “[...] pode ser pensada em termos quantitativos e qualitativos". George (1983, p. 225 e 229), propõe então uma hierarquia de cidades, onde a cidade principal é a Cidade Mundial, em seguida a Cidade Capital, a Metrópole, a Metrópole Regional, a Cidade Média, a Pequena Cidade, o Burgo e a Aldeia Centro. A partir disso, consoante com Capel (1968, p. 57, 58 e 59), existem quadro fatores que influenciam, tanto na rede como na hierarquia urbana: o primeiro é o recurso mineral, o segundo a indústria, em seguida os serviços, principalmente o turismo e o quarto a comunicação.

Assim a título de exemplo, segundo Defontaines (1938), no seu estudo sobre o crescimento da rede de cidades brasileiras, esse autor pontuou sete tipos de cidades. As primeiras são as Cidades Mineradoras, que são criadas pela descoberta de metais, preciosos ou não, como exemplos têm-se: Mariana, Outro Preto, São João Del Rei, Congonhas e Itabirito (DEFONTAINES, 1938, p. 381 e 382). Posteriormente, esses metais devem ser transportados, e assim surgem às Cidades Estradas, pois, os tropeiros necessitam de um local para pouso e consequentemente nasceram centros de população (DEFONTAINES, 1938, p. 383). A posteriori têm-se as Cidades Águas, desenvolvidas ao longo de grandes rios, como o Amazonas, São Francisco e Araguaia (DEFONTAINES, 1938, p. 384). Também, as Cidades de Estrada de Ferro, nas quais, de acordo com Defontaines (1938), no Brasil as primeiras cidades desse tipo nasceram no estado de São Paulo, por exemplo, Marília (p. 388). Já as Cidades de Trilhos ou Boca do Sertão, é o ponto de entrada para "locais desabitados do país" (DEFONTAINES, 1938, p. 388). Ainda existem as Cidades de Domingo, que durante a semana seus habitantes estão trabalhando, já no domingo essa cidade é tomada por fiéis para irem à igreja ou fazer comprar nos mercados de domingo (DEFONTAINES, 1938, 
p. 390). E por último têm-se as cidades de origem Religiosa ou Patrimônio, segundo Defontaines (1938, p. 390 e 391).

[...] o método pelo qual este tipo curioso da cidade é criado mostra a preeminência da função religiosa como o ponto inicial na concentração populacional. Geralmente um fazendeiro, ou um grupo de fazendeiros vizinhos, faziam uma doação de terras, um patrimônio, originalmente oferecido à igreja ou, mais particularmente, a algum santo, a quem a nova cidade seria dedicado e cujo nome deveria suportar. A escritura de doação foi elaborada em nome de um santo e o bispo da diocese assinava para ele (p. 390 e 391).

Assim, são essas cidades, sejam as antigas ou as contemporâneas, que formam a rede e principalmente a hierarquia urbana em determinada região. Por isso, um dos trabalhos mais importantes, nessa área é o da Teoria dos Lugares Centrais, formulado em 1933 pelo alemão Walter Christaller.

\section{A TEORIA DOS LUGARES CENTRAIS DE WALTER CHRISTALLER}

O geógrafo alemão Walter Christaller, em 1933, analisou as cidades na região sul da Alemanha, e formulou a "Teoria dos Lugares Centrais". Apesar de uma teoria ser uma simplificação da realidade, a Teoria dos Lugares Centrais oferta uma importância relevante aos estudos, principalmente sobre o processo de urbanização e a hierarquia urbana (KAPLAN, 2009, p. 73).

Para Beaujeiu-Garnier (1997, p. 472), essa teoria, tenta responder a seguinte pergunta: “existirá uma lei da distribuição espacial e estas diferenças espaciais refletirão disparidades funcionais?". Para responder a essas questões, de forma simplificada, essa teoria explana que as cidades detêm um nível de especialização máximo e tendem a se distribuir uniformemente e estão envolvidas por hinterlândias, de forma hexagonal (JONHSON, 1974, p. 140). Já segundo Ablas (1982, p. 14) “[...] a verdadeira intenção de Christaller foi justamente demonstrar que a organização das cidades não era desordenada, mas que existia uma evidente regularidade na sua disposição e na sua hierarquia". Dentro dessa perspectiva, Christaller evidenciou uma série de termos para caracterizar sua teoria, sendo os principais: a região complementar, a centralidade, o alcance de um bem, os princípios de mercado, tráfego e administrativo e os níveis hierárquicos das cidades.

A região complementar é onde o lugar central é o centro e ainda, se a região complementar pertence a um lugar central de alta ordem, essa região também será de alta 
ordem (CHRISTALLER, 1966, p. 21). Essa região influência diretamente na demanda e no consumo de diferentes tipos de bens centrais, pois dependerá de seu tamanho e de sua formação geográfica (CHRISTALLER, 1966, p. 27). De acordo com Ablas (1982, p. 25), a região complementar de Christaller é um conjunto formado pela cidade e sua região, então uma não pode existir sem a outra e vice-versa. No lugar central a densidade da população e das atividades econômicas é maior que no restante da região complementar (ABLAS, 1982, p. 25). Com isso, emerge vários tamanhos e níveis de lugares centrais, $1^{\mathrm{a}}$ ordem, $2^{\mathrm{a}}$ ordem, e assim por diante (ABLAS, 1982, p. 25). Porém, Christaller (1966, p. 45 e 46) elenca uma série de atributos que a região complementar deve possuir para suprir as necessidades do lugar central e as demais cidades e/ou municípios, são eles: o tamanho da área, a paisagem, os meios de transporte, sua natureza, a fertilidade do solo e os minerais.

Dentro dessa região complementar existe o lugar central que congrega uma centralidade. Para Christaller (1966, p. 18), a centralidade é a importância relativa de um lugar sobre a região de entorno, ou simplesmente o nível que a cidade opera suas funções centrais. Conforme Beajeau-Garnier (1997, p. 480), a centralidade trata da importância relativa do centro da cidade, em relação à sua periferia, na rede de cidades. Já para Kaplan (2009, p. 74), a centralidade refere-se ao tamanho da população de um lugar central e está diretamente relacionada ao grau de localização central para servir o entorno da população, isto é, as cidades de menores níveis da hierarquia urbana são baseadas na centralidade de um determinado lugar central. Centralidade essa que existe graças à oferta de bens e serviços centrais.

Para que exista um lugar central é necessário que esse oferte bens centrais. Em conformidade com Alvim (2009, p. 25) "os lugares centrais de primeira ordem desempenhariam funções centrais atendendo a uma ampla região”. Nessa visão a principal variável que Christaller (1966, p. 19) utilizou em sua pesquisa foi à oferta de bens e serviços, pois são eles que vão definir a centralidade de um local. Esses bens, principalmente os de alta ordem, que determinam a posição de uma cidade em uma rede hierarquizada. Esses bens e serviços centrais são produzidos e oferertados em alguns pontos centrais, a fim de serem consumidos em muitos pontos dispersos na região. Como resultado, os produtos e serviços, de alta ordem, são produzidos e ofertados em lugares centrais de alta ordem e bens e serviços de baixa ordem são produzidos e oferecidos em lugares centrais de baixa ordem, 
(CHRISTALLER, 1966, p. 19). Então, a partir de Ablas (1982), podem-se delimitar quatro tipos de bens:
a) Bens com uma dada quantidade e um preço fixo;
b) Bens com uma dada quantidade e preço fixados pelo mercado;
c) Bens cuja produção pode ser aumentada facilmente e cujo preço é fixo;
d) Bens cuja produção pode ser aumentada facilmente para os quais o preço é fixado pelo mercado (p. 33).

Essa característica fez com que Trullén e Boix (2003, p. 16) evidenciassem que a teoria das redes de cidades funciona-se igualmente a teoria dos lugares centrais, ou melhor, de forma hierárquica (p. 16). No entanto, eles observam que as relações entre as cidades não se dão somente entre as cidades menores e a cidades maiores (lugar central), mas também entre cidades de mesmo tamanho, diferente do que explica a teoria dos lugares centrais.

Esses bens e serviços centrais têm um alcance determinado, ele é "a maior distância que a população dispersa se dispõe a percorrer, objetivando adquirir um bem ou utilizar um serviço" (SILVA, 1976, p. 9). Segundo Christaller (1996, p. 22), o alcance é determinado pelas seguintes características: pelo número de habitantes no lugar central, a densidade e distribuição da população dispersada fora do lugar central, às condições de renda e estrutura social da população e a proximidade e a distância do lugar. Os bens centrais oferecidos em grandes lugares centrais geralmente têm grande alcance (CHRISTALLER, 1966, p. 50). Com isso, a influência do alcance, na oferta de bens centrais está diretamente ligada ao fato do lugar central ser maior ou menor (CHRISTALLER, 1966, p. 50). Por isso, Christaller elaborou três princípios para determinar a organização de um sistema de lugares centrais.

O primeiro princípio é o de Mercado, esse induz uma localização das cidades de um mesmo nível, "cada uma delas serve uma área hexagonal” (IPEA, v2, 2002ª p. 338). Já para Ablas (1982, p. 57), esse princípio sintetiza "a organização, o número e a localização dos lugares centrais", e depende de áreas que envolvem o bem central que é oferecido em cada lugar central de diversas ordens.

O segundo princípio é o de Tráfego ou Transporte, esse visa uma minimização dos eixos de circulação (IPEA, v2, 2002a , p. 338). E "os lugares centrais devem estar alinhados nas estradas que irradiam de um lugar central que pode ser considerado como o centro do sistema" (ALBAS, 1982, p. 57).

E o último é o princípio Administrativo, no qual a principal característica é a não existência de uma imposição dentro das regiões de influência (IPEA, v2, 2002a , p. 338). Para 
Ablas (1982, p. 60), esse princípio também pode ser chamado de socioeconômico, porque sua tarefa é organizar o todo "[...] em pares menores de tal forma que cada uma dessas partes possa ser considerada com uma unidade administrativa”. Com base nisso, foi possível, para Christaller estabelecer quatro níveis hierárquicos de lugares centrais.

Christaller (1966) dividiu as cidades, em quadro níveis hierárquicos: (1) Central Places of a Higher Order (alta ordem); (2) Central Places of a Lower Order (baixa ordem), (3) Central Places of the Lowest Order (baixíssima ordem) e ainda (4) Auxiliary Central Places (centros auxiliares).

Portanto, a Teoria dos Lugares Centrais trata da formação e configuração de uma Rede Hierárquica de cidades.

\section{ASPECTOS METODOLÓGICOS DA PESQUISA}

Para o tratamento dos dados utilizou-se a técnica matemático-estatística de Análise de Componentes Principais. Dessa maneira, para nortear as análises sobre a hierarquia urbana da MRTMAP, a mesorregião foi subdividida em três porções: Poção Central; Porção Leste e Porção Oeste (Figura 1).

A Análise de Componentes Principais consiste na combinação, linear, de variáveis que são altamente correlacionadas e que obtém a maior variabilidade dos dados analisados. Essa combinação se dá por meio de Matrizes, autovalores e autovetores ${ }^{2}$. A partir de então, se calcula o "Escore"”. A sistemática da ACP começa com a matriz de dados brutos, que no caso é constituída de 12 (variáveis / atributos) colunas e 66 linhas (municípios / indivíduos). Elas representam 18,18\% do número de indivíduos, o que permite a utilização ACP. Nesse processo deve-se ter em mente que para a aplicação dessa técnica as variáveis-atributos devem ser menores, em números, que as unidades espaciais-indivíduos, no caso, municípios. Em seguida é necessário padronizar as variáveis e torná-las adimensionais ${ }^{4}$. Para essa padronização foram utilizadas: as próprias variáveis; suas respectivas médias e seus respectivos desvios padrões. O próximo processo é o de calcular a matriz de correlação, dos

\footnotetext{
${ }^{2}$ Os Autovetores são os pesos da combinação linear; já os Autovalores quando somados o resultado deve ser igual ao número de variáveis.

${ }^{3}$ Nesta pesquisa o Escore é o resultado da aplicação da ACP que será utilizado para hierarquizar os municípios da mesorregião.

${ }^{4}$ Em análise dimensional, uma grandeza adimensional ou número adimensional é um número desprovido de qualquer unidade física que o defina - portanto é um número puro.
} 
dados padronizados. Cabe lembrar que as variáveis devem ser altamente correlacionadas. Sendo assim, a partir da matriz de correção são calculados os autovalores e autovetores. Posteriormente é calculada a variância total dos dados da componente. E para um melhor resultado, neste trabalho optou-se por considerar a variância acima de 50\%, com vistas a exprimir uma um resultado confiável. Logo depois é necessário calcular a correlação entre a componente principal e as variáveis, que dará o Escore, ou nota de cada indivíduo. Cabe colocar também, como nota de esclarecimento, que o Escore obtido por essa sistemática será usado com um dado ordinal, ou seja, classificando a ordem dos municípios do primeiro até o sexagésimo sexto, e como base matemática a ser usada na Teoria dos Lugares Centrais.

Figura 01: Localização e Nova divisão dos municípios da Mesorregião do Triângulo Mineiro e Alto Paranaíba.

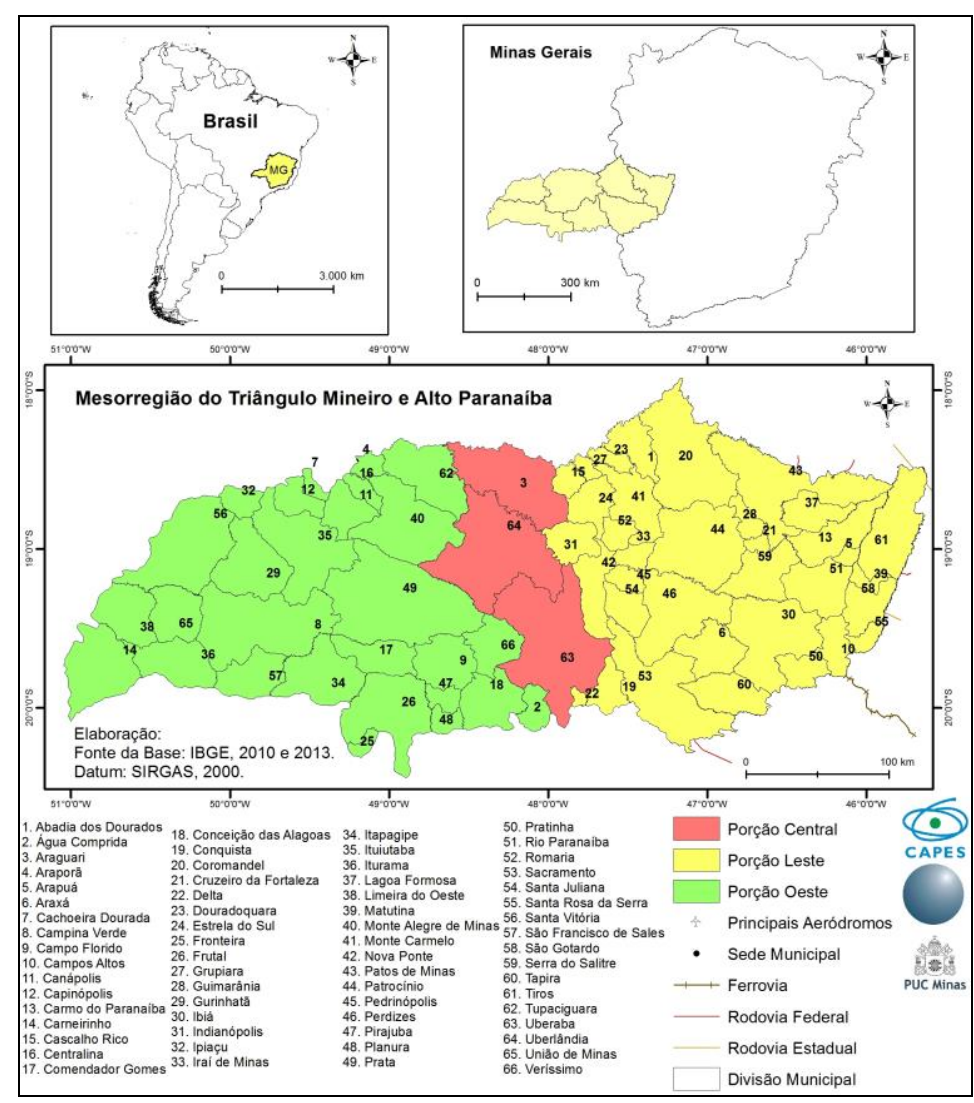

Fonte: Autores, 2017.

Essa técnica foi realizada no software Ninna PCA, desenvolvido por Alencar (2009).

Com isso, os escores da primeira componente obtidos, via ACP, foram reescalonados para uma melhor comparação entre eles, com variabilidade centrada entre 1 e 10 . Para o Novo Valor tem-se: 


$$
\mathrm{NV}=\frac{\left(\text { fim }- \text { início). }\left(\mathrm{x}_{\mathrm{i}}-\text { menor }\right)\right.}{\text { (maior }- \text { menor })}+\text { início } \text { No qual, } \mathrm{NV}=\text { Novo Valor, } \mathrm{x}_{\mathrm{i}}=\text { Variável original, }
$$

Inicio $=$ Valor 0 (zero), Fim $=$ Valor $10(\mathrm{dez})$, Maior $=\mathrm{x}$, Menor $=\mathrm{y}$.

Logo, os resultados obtidos na aplicação da técnica ACP foram mapeados. Vale ressaltar que a técnica utilizada para mapear, ou seja, o tamanho dos intervalos das classes foi à quebra natural. E com isso o índice obtido foi utilizado para classificar os municípios da mesorregião, de acordo com Christaller (1966) em: (1) central places of a higher order (alta ordem); (2) central places of a lower (baixa ordem), (3) of the lowest order (baixíssima ordem) e ainda (4) auxiliary central places (centros auxiliares). E ainda propor uma nova hierarquia delineada pela proposta de Christaller e a aplicação da ACP.

Quadro 1: Variáveis utilizadas para hierarquizar os municípios da MRTMAP.

\begin{tabular}{|c|c|c|}
\hline VARIÁVEIS & INFORMAÇÃO & FONTE \\
\hline POPULAÇÃO TOTAL & $\begin{array}{l}\text { População de meio período, para os anos de } \\
2000 \text { e } 2010 .\end{array}$ & IBGE / Censos Demográficos \\
\hline PRODUTO INTERNO BRUTO TOTAL & Em mil (R\$), para os anos de 2000 e 2010 & IPEA \\
\hline PRODUTO INTERNO BRUTO INDUSTRIAL & Em mil (R\$), para os anos de 2000 e 2010 & IPEA \\
\hline $\begin{array}{l}\text { PRODUTO INTERNO BRUTO COMÉRCIO E } \\
\text { SERVIÇOS }\end{array}$ & Em mil (R\$), para os anos de 2000 e 2010. & IPEA \\
\hline PRODUTO INTERNO BRUTO AGROPECUÁRIO & Em mil (R\$), para os anos de 2000 e 2010. & IPEA \\
\hline $\begin{array}{c}\text { ÍNDICE DE DESENVOLVIMENTO HUMANO } \\
\text { MUNICIPAL }\end{array}$ & $\begin{array}{l}\text { Variável entre } 0 \text { e } 1 \text {, para os anos de } 2000 \text { e } \\
2010 .\end{array}$ & $\begin{array}{c}\text { ATLAS DO } \\
\text { DESENVOLVIMENTO } \\
\text { HUMANO_2013 }\end{array}$ \\
\hline $\begin{array}{c}\text { ÍNDICE DE DESENVOLVIMENTO HUMANO } \\
\text { MUNICIPAL DE EDUCAÇÃO }\end{array}$ & $\begin{array}{l}\text { Variável entre } 0 \text { e } 1 \text {, para os anos de } 2000 \text { e } \\
2010 .\end{array}$ & $\begin{array}{c}\text { ATLAS DO } \\
\text { DESENVOLVIMENTO } \\
\text { HUMANO_2013 }\end{array}$ \\
\hline $\begin{array}{c}\text { ÍNDICE DE DESENVOLVIMENTO HUMANO } \\
\text { MUNICIPAL DE RENDA }\end{array}$ & $\begin{array}{l}\text { Variável entre } 0 \text { e } 1 \text {, para os anos de } 2000 \text { e } \\
\qquad 2010 .\end{array}$ & $\begin{array}{c}\text { ATLAS DO } \\
\text { DESENVOLVIMENTO } \\
\text { HUMANO_2013 }\end{array}$ \\
\hline $\begin{array}{l}\text { ÍNDICE DE DESENVOLVIMENTO HUMANO } \\
\text { MUNICIPAL DE LOGENVIDADE }\end{array}$ & $\begin{array}{l}\text { Variável entre } 0 \text { e } 1 \text {, para os anos de } 2000 \text { e } \\
2010 .\end{array}$ & $\begin{array}{c}\text { ATLAS DO } \\
\text { DESENVOLVIMENTO } \\
\text { HUMANO_2013 }\end{array}$ \\
\hline $\begin{array}{l}\text { PROPORÇÃO DE PESSOAS OCUPADAS EM } \\
\text { RELAÇÃO À POPULAÇÃO TOTAL }\end{array}$ & $\begin{array}{c}\text { População ocupada de meio período / } \\
\text { População total de meio período, para os anos } \\
\text { de } 2000 \text { e } 2010 .\end{array}$ & $\begin{array}{l}\text { Ministério do Trabalho e } \\
\text { Emprego - RAIS. }\end{array}$ \\
\hline $\begin{array}{l}\text { PROPORÇÃO DE PESSOAS OCUPADAS NO } \\
\text { COMERCIO E SERVIÇOS EM RELAÇÃO À } \\
\text { POPULAÇÂOO TOTAL }\end{array}$ & $\begin{array}{l}\text { População ocupada no Comércio e Serviços de } \\
\text { meio período / População total de meio } \\
\text { período, para os anos de } 2000 \text { e } 2010 .\end{array}$ & $\begin{array}{l}\text { Ministério do Trabalho e } \\
\text { Emprego - RAIS. }\end{array}$ \\
\hline $\begin{array}{c}\text { NÚMERO DE EMPRESAS ATUANDO NO } \\
\text { COMÉRICO E SERVIÇO }\end{array}$ & $\begin{array}{c}\text { Número total de empresas atuando no comércio } \\
\text { e serviços, para os anos de } 2000 \text { e } 2010 .\end{array}$ & $\begin{array}{l}\text { Ministério do Trabalho e } \\
\text { Emprego - RAIS. }\end{array}$ \\
\hline
\end{tabular}

Fonte: Autores, 2016. 


\section{ANÁLISE DA HIERARQUIA URBANA NA MRTMAP}

A Hierarquia Urbana é o nível hierárquico que as unidades espaciais ocupam dentro de uma região. Contudo, esse nível hierárquico não é fixo no tempo e no espaço, de modo que as a hierarquia pode ser alterada ou mantida ao longo do tempo. Assim, de acordo com a Teoria dos Lugares Centrais de Christaller, além de analisar a posição hierárquica de um lugar central, subentende-se nesta pesquisa município, é necessário verificar, igualmente, sua região complementar, sua centralidade, seus princípios de mercado, transporte e administrativo e seus diferentes níveis hierárquicos. Todavia, é necessário, nesta pesquisa, que se crie uma nova hierarquia, a fim de analisar de forma concreta a hierarquia urbana da MRTMAP.

A partir disso, ao analisar as principais diferenças entre a hierarquia urbana dos municípios da MRTMAP, entre os anos de 2000 e 2010, as principais transformações ocorreram a partir da nona posição em diante (Tabela 1).

Tabela 1: As 15 primeira posições da Hierárquica dos municípios da MRTMAP - 2000 e 2010.

\begin{tabular}{l|c|c|l|c|c}
\hline \multicolumn{1}{c|}{ MUNICÍPIO } & $\begin{array}{c}\text { POSIÇÃO NA } \\
\text { HIERRQUIA } \\
\mathbf{2 0 0 0}\end{array}$ & $\begin{array}{c}\text { RESULTADO } \\
\text { ACP 2000 }\end{array}$ & MUNICÍPIO & $\begin{array}{c}\text { POSIÇÃO NA } \\
\text { HIERARQUIA } \\
\mathbf{2 0 1 0}\end{array}$ & $\begin{array}{c}\text { RESULTADO } \\
\text { ACP 2010 }\end{array}$ \\
\hline Uberlândia & 1 & 10 & Uberlândia & 1 & 10 \\
Uberaba & 2 & 6,64 & Uberaba & 2 & 6,45 \\
Patos de Minas & 3 & 4,24 & Patos de Minas & 3 & 4,29 \\
Araxá & 4 & 4,06 & Araxá & 4 & 4,12 \\
Araguari & 5 & 4,06 & Araguari & 5 & 3,93 \\
Patrocínio & 6 & 3,59 & Patrocínio & 6 & 3,25 \\
Ituiutaba & 7 & 3,46 & Ituiutaba & 7 & 3,19 \\
Frutal & 8 & 3,15 & Frutal & 8 & 2,79 \\
Iturama & 9 & 2,98 & Iturama & 9 & 2,78 \\
Ibiá & 10 & 2,82 & Sacramento & 10 & 2,6 \\
Nova Ponte & 11 & 2,81 & Monte Carmelo & 11 & 2,58 \\
Coromandel & 12 & 2,64 & São Gotardo & 12 & 2,42 \\
Sacramento & 13 & 2,62 & Perdizes & 13 & 2,41 \\
Carmo do Paranaíba & 14 & 2,56 & Ibiá & 14 & 2,34 \\
Araporã & 15 & 2,53 & Coromandel & 15 & 2,29 \\
\hline
\end{tabular}

Fonte: Resultados ACP, 2016.

Para uma análise mais apurada é necessário verificar, em relação aos municípios da mesorregião, o número dos que evoluíram, retraíram e os que mantiveram a mesma posição hierárquica na região. 
Na mesorregião existe munícipios que não mudaram de nível hierárquico, foram eles: Uberlândia, Uberaba e Araguari, na Porção Central da MRTMAP; Ituiutaba, Frutal, Iturama e Centralina, na Porção Oeste, contudo esse último ocupou, nos dois períodos, a penúltima posição hierárquica da região e Araxá, Patos de Minas e Patrocínio, na Porção Leste. Isso vai de encontro ao que Johnson (1974, p. 136), afirma que grandes cidades tendem a organizar o seu entorno, mas nesse contexto são as cidades médias, por exemplo, Uberlândia, na porção central, Ituiutaba e Frutal no oeste e Araxá e Patos de Minas no leste.

Dentre os municípios que mais evoluíram, ou seja, que ascenderam na hierarquia, primeiramente, na Porção Oeste, têm-se: Cachoeira Dourada, Capinópolis, União de Minas, Prata, Itapagipe, Conceição das Alagoas, Canápolis, Campo Florido, Carneirinho, Limeira do Oeste e Santa Vitória. No entanto, os municípios que mais subiram de nível hierárquico nos períodos de 2000 a 2010, na Porção Oeste foram os cinco últimos. Com destaque para: Carneirinho (39 para a $\left.16^{\circ}\right)$; Limeira do Oeste da $\left(59^{\mathrm{a}}\right.$ para a $\left.37^{\mathrm{a}}\right)$; e Santa Vitória, a qual obteve o maior ganho, passando da posição $52^{\circ}$ em 2000, para a $23^{a}$ em 2010. Em Santa Vitória, isso ocorreu devido, especialmente à instalação, em 2008, da empresa Santa Vitória Açúcar e Álcool (SVAA) que é a junção entre a The Dow Chemical Company e a Mitsui \& Co Ltda. Segundo dados dessa empresa, ela tem capacidade de processamento de 2,7 milhões de toneladas de cana-de-açúcar e produção de até 240 milhões de litros de etanol por safra, em uma área de 36 mil hectares de plantação e atuando com cerca de 1.100 funcionários diretos (SVAA, 2015). Assim, essa industrial é um dos fatores que Capel (1968, 57,58 e 59) coloca que influência na hierarquia de uma região.

Na Porção Leste os municípios que mais evoluíram foram 17, entre 2000 e 2010. Desse número podem-se destacar: Tapira (46 para a 20 $)$; Rio Paranaíba (37 para $18^{\mathrm{a}}$ ) Pratinha $\left(61^{\mathrm{a}}\right.$ para $\left.36^{\mathrm{a}}\right)$ e Estrela do Sul $\left(62^{\mathrm{a}}\right.$ para a $\left.45^{\mathrm{a}}\right)$. O município que mais se destaca na questão da evolução foi Tapira. A economia desse município gira em torno da extração de fosfato. Segundo dados do Ministério das Minas e Energia, a principal jazida desse mineral se encontra justamente em Tapira, no qual é utilizado na produção de fertilizantes NPK, (2009, p. 7).

Por outro lado, existem também aqueles municípios que perderam posições entre os anos de 2000 e 2010. Na Porção Oeste da região são 13 municípios nessa situação. Com isso, podemos destacar: Fronteira, Monte Alegre de Minas, Campina Verde, Ipiaçu, São Francisco de Sales, Comendador Gomes e Araporã. 
Na Porção Leste os municípios que perderam posições foram 14. Desses, os que mais retraíram foram: Romaria, Indianópolis, Pedrinópolis, Nova Ponte, Carmo do Paraíba, Campos Altos Cruzeiro da Fortaleza e Guimarânia.

Ainda no contexto de perda de posição, não é uma heresia pensar que as cidades médias das três porções da região funcionam claro em escala menor, como expõem Santos (1981, p. 145), como uma "macrocefalia".

Portanto, na MRTMAP ocorreu, particularmente, a partir da posição nona posição hierárquica, inúmeras mudanças de posição. Contudo, pode-se verificar que o número de municípios que evoluíram e retraíram entre 2000 e 2010 foram exatamente o mesmo, isto é, 28. Vale ressaltar ainda que em termos do número de municípios com maior retração que foram oito no oeste e nove no leste. Fato constatado esse que ocorreu também nos municípios que obtiveram maior elevação hierárquica, sendo no oeste cinco e no leste quatro. Entretanto, somente essa análise não é suficiente para entender a Hierarquia Urbana da MRTMAP, então é necessário um subsidio teórico, ou seja, nessa pesquisa da Teoria dos Lugares Centrais.

\section{A HIERARQUIA URBANA DA MRTMAP E A TEORIA DOS LUGARES CENTRAIS}

Dentro de uma hierarquia urbana existem aqueles municípios que são considerados lugares centrais. Nesses lugares encontram-se também suas regiões complementares, uma centralidade, alguns princípios que os regem e seus diferentes níveis hierárquicos.

Como exposto anteriormente pode-se pensar que a MRTMAP é a região complementar do Lugar Central de Alta Ordem - Uberlândia, pois a região complementar é onde o lugar central é o centro. Entretanto, apesar de ser um município forte dentro da mesorregião, existem outros municípios que fazem igualmente, o papel de lugar central, contudo em uma ordem inferior. Com isso, têm-se os municípios de Uberaba, Patos de Minas, Frutal, Ituiutaba, Araxá e Patos de Minas, que fazem às vezes de um lugar central. Além desses municípios terem posição relevante na hierarquia, eles também comandam suas respectivas microrregiões.

Sobre a centralidade é válido ressaltar que essa é uma importância relativa de um município sobre sua região complementar. Com isso, o município da MRTMAP, tanto em 2000 como em 2010, que tem a maior centralidade, que chega até a ultrapassar as fronteiras da mesorregião, é Uberlândia. Todavia, de natureza igual, como foi explanado anteriormente, 
outros municípios tem centralidades relevantes, no contexto da região. Tem-se, primeiramente, Uberaba que do total de empresas que atuam no município, nos setores de indústria, agropecuária e comércio e serviços, esse último é responsável por 63,65\% do total, em 2000 e aumentou para 75,51\%, em 2010. Igualmente têm-se Patos de Minas (62,50\% 2000 e 69,48 - 2010) e Araxá (61,91 - 2000 e 68,10 - 2010) e em um nível um pouco inferior, Ituiutaba (56,26 - 2000 e 65,39 - 2010). Assim, com esse contingente de empresas atuando no comércio e serviço, fica evidente o porquê de suas posições hierárquicas e de suas centralidades na região.

No que se refere ao princípio de mercado que é regido pela oferta de bens e serviços centrais. Como visto anteriormente, a centralidade de Uberlândia lhe afirma como o grande polo comercial da região, contudo, atuando de forma microrregional há outros municípios. Esses municípios não servem a uma área hexagonal, como afirma Christaller. Mas, as suas respectivas microrregiões, pois fornecem bens centrais de diversas ordens, particularmente para seus vizinhos mais próximos, ou seja, para aqueles de suas respectivas microrregiões. $\mathrm{O}$ município de Ituiutaba, por exemplo, mantém relações importantes com todos os municípios de sua microrregião.

Já quanto ao princípio de Tráfego ou Transporte, existe, na maior parte da região, uma minimização dos eixos de circulação. No qual, principalmente na Porção Central da região os lugares centrais estão quase alinhados nas estradas nos sentidos norte-sul e sul-norte, isto é, são os centros do sistema urbano-regional e da rede.

Assim, no princípio Administrativo ou Socioeconômico, no qual é o que organiza toda a região, Uberlândia é o grande lugar central, pois, por exemplo, se a região conquistasse sua independência de Minas Gerais, esse município seria a capital administrativa da nova unidade da federação. Com isso, é possível estabelecer níveis hierárquicos entre os municípios.

Os níveis hierárquicos dos lugares centrais na MRTMAP pouco se alteraram nas nove primeiras posições entre os decênios de 2000 a 2010 (Figura 2).

No que tange o Lugar Centra de Alta Ordem, tanto em 2000, quanto em 2010 é o município de Uberlândia. Já ao se analisar a posição dos lugares centrais de Baixa Ordem, nota-se mudanças consideráveis. Em 2000, eram dois localizados na Porção Oeste, Ituiutaba e Frutal, dois na Porção Central, Araguari e Uberaba e mais três na porção leste, Patos de Minas, Patrocínio e Araxá. Em 2010 ocorreu uma mudança relevante, em específico com o nível hierárquico do município de Frutal. Esse perdeu uma posição hierárquica, passando para 
um lugar central de baixíssima ordem, no ano de 2010, de acordo com o método estatístico aplicado, ACP e a divisão em classes por quebra natural.

Figura 2: Mapa da Hierarquia Urbana dos municípios da MRTMAP - 2000 e 2010.

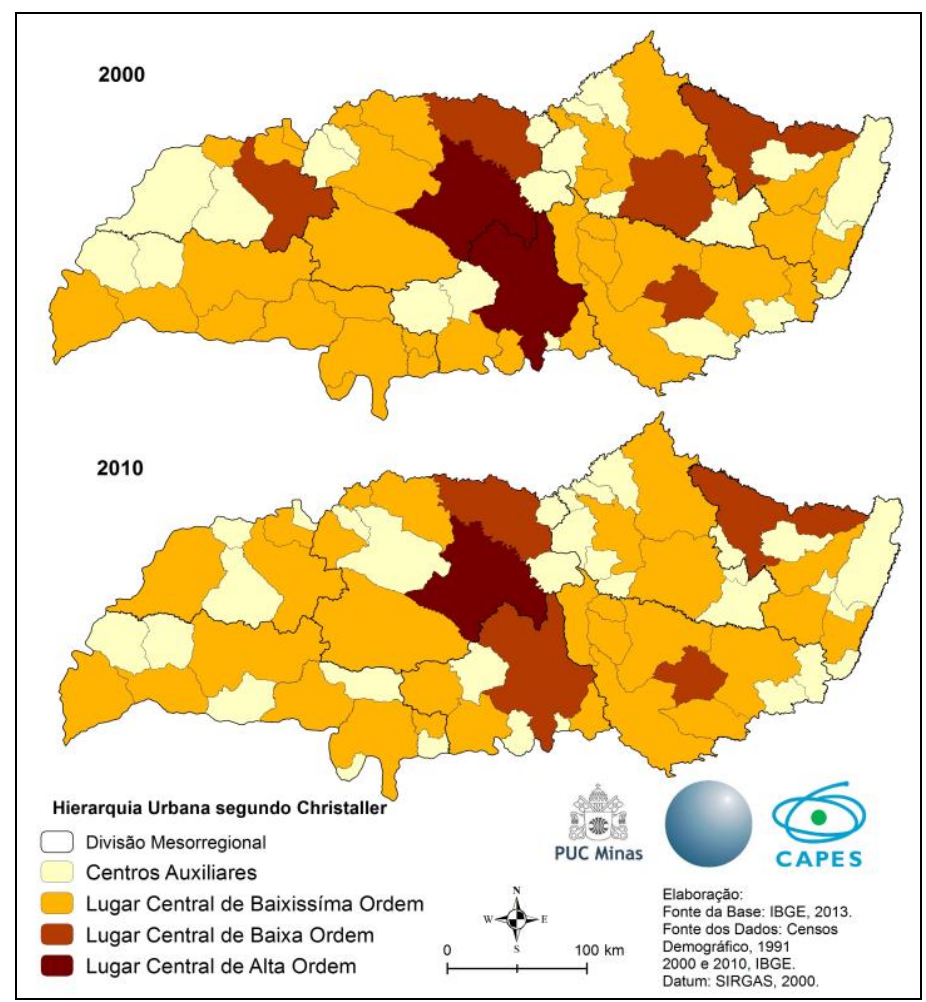

Fonte: Autor, 2017.

No nível hierárquico de Baixíssima Ordem, na Porção Central, não havia nenhum município, tanto em 2000, quanto em 2010, fato esse que ocorreu também com os centros auxiliares. Na Porção Oeste existiram 13 municípios, em 2000, com baixíssima ordem, número que não se alterou em 2010, contudo esse número não se alterou, por que Frutal foi rebaixada de baixa para baixíssima ordem e Planura passou de baixíssima ordem em 2000, para centro auxiliar em 2010.

No nível hierárquico dos Centros Auxiliares na Porção Oeste, em 2000, o número foi de 13 municípios e em 2010 de 14. Os munícipios dessa porção que retraíram hierarquicamente, entre 2000 e 2010, foram: Monte Alegre de Minas, Comendador Gomes, Fronteira, Planura e Campina Verde. No entanto, os que evoluíram foram Capinópolis, Santa Vitória, Campo Florido e Carneirinho. Na Porção Leste o número de municípios com baixíssima ordem em 2000 foi de 14, e em 2010 caiu para 13. A principal diferença foi à perda de posição hierárquica de três municípios: Cruzeiro da Fortaleza, Arapuá e Campos 
Altos, passando em 2010, para centros auxiliares. Todavia, dois municípios subiram um nível em 2010, são eles Tapira e Rio Paranaíba. Já quanto aos centros auxiliares da Porção Leste eram 18 municípios, em 2000, e passou a ser, em 2010, 19, devido ao número de munícipios que passaram de baixíssima ordem para centos auxiliares, no caso três e somente dois evoluíram hierarquicamente.

\section{PROPOSTA PARA UMA NOVA HIERARQUIA URBANA NA MRTMAP}

Apesar de o arcabouço teórico ser essencial à análise, é necessário ir além. Para isso foi proposta uma nova hierarquia, ainda com base em Christaller (1966), mas desta feita com o acréscimo de mais dois níveis hierárquicos, passando assim a existir seis níveis hierárquicos, a saber: Lugar Central de Ordem Superior, Lugar Central de Alta Ordem, Lugar Central de Média Ordem, Lugar Central de Baixa Ordem, Lugar Central de Baixíssima Ordem e os Centros Auxiliares.

Desse modo, ao analisar a MRTMAP desta nova forma, assim como nos níveis de Christaller, somente há um lugar central na região, nesse caso de Ordem Superior, que é Uberlândia, tanto em 2000, como em 2010.

Não obstante, foram nos demais níveis hierárquicos que houve as maiores mudanças, entre 2000 e 2010 (Figura 3). No nível de Alta Ordem, em 2000 existiam quatro municípios, Araguari, Uberaba, Araxá e Patos de Minas, já em 2010, somente três, Uberaba, Araxá e Patos de Minas, pois, Araguari se tornou de Média Ordem. Porém, o que chama mais atenção, na nova hierarquia é novamente a maior dinâmica da porção leste em relação a oeste. Pois, os principais municípios da porção oeste, Ituiutaba e Frutal estão agora na Média Ordem, tanto em 2000, quanto em 2010, juntamente com Iturama e Araporã, isto é, nenhum município da porção oeste tem nível hierárquico de alta ordem nos dois períodos analisados.

Já na porção leste, os municípios que estão no mesmo nível de Ituiutaba e Frutal (municípios esse que estão na Porção Oeste) são Coromandel, Patrocínio, Nova Ponte, Sacramento, Ibiá e Carmo do Paranaíba e Rio Paranaíba, em 2000. E em 2010 na porção oeste, Araporã deixa de ser de média ordem, diminuindo assim o número de municípios nesse nível para somente três. Na porção leste, em 2010, houve também uma diminuição, passando de seis para cinco municípios de média ordem, onde Coromandel, Nova Ponte, Rio Paranaíba e Ibiá retraíram, mas São Gotardo, Perdizes e Monte Carmelo subiram na hierarquia. 
Figura 3: Mapa da Nova Hierarquia Urbana dos municípios da MRTMAP - 2000 e 2010.

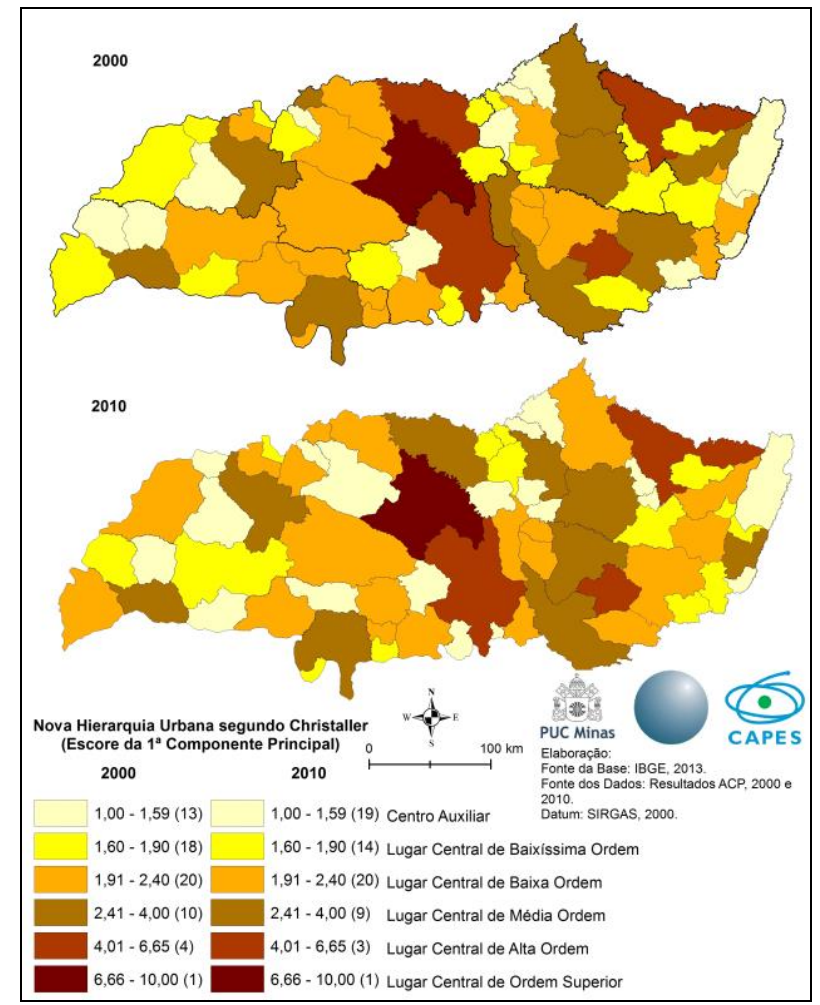

Fonte: Autor, 2017.

Contudo, essa constatação ocorrida no nível hierárquico de média ordem não se repete no de baixa ordem. Tanto em 2000, como em 2010, na porção oeste existiam 11 municípios de baixa ordem e na porção leste nove. A maior mudança nessa nova hierarquia é nos níveis de baixíssima ordem e nos centros auxiliares. No primeiro, em 2000, existiam 18 municípios e houve uma diminuição para 14, e nos centros auxiliares ocorreu um aumento de 13 para 19 municípios, em toda a mesorregião. Com isso, na porção oeste, em 2000 eram oito municípios e em 2010 diminuiu para cinco.

Na porção leste, em 2000 eram dez e em 2010 nove. Quanto aos centros auxiliares, na porção oeste, em 2000 eram somente cinco e em 2010 nove. E na porção leste, em 2000 eram oito em 2010 dez.

Portanto, primeiramente no nível hierárquico dos municípios da MRTMAP entre 2000 e 2010 ocorreram várias mudanças. Alguns municípios melhoraram sua posição hierárquica, outros perderam posição. Uberlândia continuou como o grande polo hierárquico da região, ou seja, o Lugar Central de Alta Ordem, segundo Christaller e na nova hierarquia o Lugar Central de nível Superior. Além disso, pode-se notar também que Uberaba vem perdendo 
influência na região, embora não tenha sofrido alteração no nível hierárquico. Afinal, municípios como Patos de Minas, Araxá, Ituiutaba e até mesmo Iturama vem ganhado notoriedade dentro da mesorregião. Sobre as porções da região, a porção central é a mais evoluída, contudo a porção leste vem se desenvolvendo de forma significativa. Já a porção oeste, também se desenvolve, todavia numa velocidade inferior. Por exemplo, o município de Frutal no oeste, o qual ainda necessita de melhorias, especialmente em sua infraestrutura, por exemplo, de transporte público intermunicipal. Mas, o que mais chama a atenção são os municípios de Ituiutaba e os que estão localizados no pontal do triângulo, Carneirinho, Limeira do Oeste e Santa Vitória, que apresentaram aumento expressivo de seus níveis hierárquico, de 2000 para 2010. Assim, pode-se verificar que a hierarquia urbana, mesmo evidenciando as diferenças entre os municípios, na MRTMAP ela se mostra bem estruturada, diferentemente daquela de outras regiões localizadas em áreas menos favorecidas. $\mathrm{O}$ que também pode ser percebido na análise da migração interna de pessoas entre 2000 e 2010.

\section{CONSIDERAÇÕES FINAIS}

O espaço geográfico, particularmente o regional é divido principalmente por cidades que tem importâncias diferentes no sistema urbano. Dessa maneira, a hierarquia urbana, analisada pelo viés da Teoria dos Lugares Centrais de Walter Christaller (1966), em conjunto com a técnica de Análise Componentes Principais, confirmou o que na MRTMAP existem alguns municípios que são lugares centrais, mas que o verdadeiro lugar central de toda região é Uberlândia. Evidenciou da mesma forma que o alcance de municípios como: Patos de Minas e Ituiutaba eram locais, sendo de forma mais evidente em suas respectivas microrregiões. Porém, foi visto, por exemplo, na microrregião de Frutal, a divisão do protagonismo hierárquico entre Frutal e Iturama. Igualmente verificou-se que o maior alcance na mesorregião, nos dois períodos analisados foi de Uberlândia. Município tido como o Lugar Central de Alta Ordem, na hierarquia de Christaller e de Ordem Superior na proposta de nova hierarquia.

Do mesmo modo, pode-se afirmar que a Porção Central é a mais dinâmica da MRTMAP, especialmente por abarcar o principal polo da região, Uberlândia. Igualmente, a Porção Leste da mesorregião era mais desenvolvida e dinâmica que a Porção Oeste, dentro do período de tempo analisado. Contudo, o que se percebeu é uma evolução significativa da 
Porção Oeste, contribuindo assim para um desenvolvimento mais equiparado destas porções da mesorregião.

Desse modo, a Mesorregião do Triângulo Mineiro e Alto Paranaíba é uma região de extrema importância para o contexto nacional, pois, liga o Norte e o Sul do Brasil. Com base nisso, acredita-se que seria pertinente à criação de um órgão ou comitê, assim como ocorre no gerenciamento de bacias hidrográficas, para planejar o desenvolvimento regional da MRTMAP, e/ou mesmo para o planejamento das demais mesorregiões de Minas Gerais. Para esse fim, a longo e médio prazo, valeria à pena, desde que houvesse vontade política, criar mais uma subdivisão geográfica além da divisão entre Estado e Município, como existe em alguns países europeus. Isso permitiria um planejamento regional voltado para as potencialidades de cada área. Na MRTMAP isso seria interessante, pois promoveria o progresso do setor agropecuário, tendo sempre em vista a sustentabilidade.

Por fim, a MRTMAP como região de extrema importância para Minas Gerais e para o Brasil, merece maiores estudos para que continue avançando. Afinal, ela dispõe de relações não só em seu contexto estadual, Minas Gerais, mas também com estados, como Goiás e Mato do Grosso do Sul, mas principalmente com São Paulo.

\section{REFERÊNCIAS}

ABLAS, Luiz Augusto de Queiroz. A Teoria do Lugar Central: bases teóricas e evidências empíricas: estudo de caso de São Paulo. São Paulo: Instituto de Pesquisas Econômicas, 1982. 208 p.

ALVIM, Ana Márcia Moreira. Análise da rede urbana de Minas Gerais: a partir dos fluxos migratórios. 2009. 187f. (Tese Doutorado). Programa de Pós-graduação em Geografia: Tratamento da Informação Espacial, Pontifícia Universidade Católica de Minas Gerais, Belo Horizonte, 2009. Disponível em: <http://www.biblioteca.pucminas.br/teses/TratInfEspacial_AlvimAM_1.pdf >. Acesso em: 10 out. 2013.

BEAUJEU-GARNIER, Jaqueline. Geografia Urbana. Tradução: Raquel Soeiro de Brito. 2. ed. Lisboa: Fundação Calouste Gulbenkiam, 1997, 360 p.

BESSA, Kelly. A Dinâmica da Rede Urbana no Triângulo Mineiro: convergências e Divergências entre Uberaba e Uberlândia. Uberlândia: [s.n], 2007. 
CAPEL, Horácio. La red urbana española y la nueva demarcación judicial. Revista de Geografía, vol. II, no 1, Universidad de Barcelona, 1968, p. 56-65. (A). Disponível em: <http://www.raco.cat/index.php/RevistaGeografia/article/view/50272/56617>>. Acesso em: 23 abr. 2015.

CHRISTALLER, Walter. Central Places in Southern Germany. Tradução de Carlisle W. Baskin. New Jersey: Prentice-Hall, 1966, p. 236.

DEFONTAINES, Pierre. The origin and growth of the Brazilian network of town. Geographical Review. New York. v. 28, n. 3., 1938, 379 - 399 p. Disponível em: <http://www.jstor.org/discover/10.2307/209737?uid=32769\&uid=3737664\&uid=5909624\&ui $\mathrm{d}=2 \&$ uid $=3 \&$ uid=67\&uid=32768\&uid=62\&sid=21106390952051 $>$. Acesso em: 23 abr. 2015.

GEORGE, Pierre. Geografia Urbana. 1909. Tradução: Grupo de Estudos Franceses de Interpretação e Tradução. DIFEL, São Paulo, 1983, p. 236.

INSTITUTO BRASILEIRO DE GEOGRAFIA E EESTATÍSTICA. Divisão Regional do Brasil em Mesorregiões e Microrregiões Geográficas. Rio de Janeiro, IBGE, 1990. Disponível em: http://biblioteca.ibge.gov.br/visualizacao/monografias/GEBIS\%20\%20RJ/DRB/Divisao\%20regional_v01.pdf. Acesso em: 29 out, 2015.

INSTITUTO DE PESQUISAS ECONÔMICAS APLICADAS. Estudos Básicos para Caracterização da Rede Urbana. In: Coleção Caracterização e Tendências da Rede Urbana do Brasil. Brasília, v.2. 2002, 396 p. Disponível em: <http://www.ipea.gov.br/portal/images/stories/PDFs/livros/livros/livro_caracterizacao_tenden cias_v02.pdf $>$. Acesso: 23 abr. 2015.

INSTITUTO DE PESQUISAS ECONÔMICAS APLICADAS. IPEA data. Brasília. IPEA. Disponível em: <http://www.ipeadata.gov.br/ >. Acesso em: 24 set. 2014.

JOHNSON, J. H. Geografía Urbana. Barcelona: OiKos-tau, 1974, 280 p.

KAPLAN, David H; WHELER, James O; HOLLOWAY, Steven R. Urban Geography. 2 ed. Hoboken: Wiley, 2009, 484 p.

MINISTÉRIO DE MINAS E ENERGIA. Relatório Técnico 53: Perfil do Fosfato. Projeto ESTAL. Projeto De Assistência Técnica Ao Setor De Energia. Brasília. MME, Brasília, 2009 , 55

p.

Disponível

em: 
<http://www.mme.gov.br/documents/1138775/1256650/P29_RT53_Perfil_do_Fosfato.pdf/48 caf3fe-b399-4032-9337-d63ce39b218d >. Acesso em: 29 dez. 2015.

PLA, Laura E. Analisis multivariado: metodo de componentes principales. Fálcon Venezuela: Universidad Nacional Experimental Francisco de Miranda, 1986. 94 p.

SANTA VITÓRIA AÇÚCAR E ÁLCOOL - SVAA. Quem somos. Santa Vitória, 2015. Disponível em: 〈http://www.ussantavitoria.com.br/?page_id=6 >. Acesso em: 10 out, 2015.

SANTOS, Milton. Manual de Geografia Urbana. Tradução: Antônia D. E e Maria Auxiliadora. São Paulo: HUCITE, 1981, p. 204.

TRULLÉN, Joan. BOIX, Rafael D. Barcelona, metrópolis policéntrica en red. Departament d'Economia Aplicada, v. 3, n. 3, Barcelona, 2003. 1 - 30 p. Disponível em: $<$ http://www.researchgate.net/profile/Rafael_Domenech/publication/36730245_Barcelona_m etropolis_policentrica_en_red/links/0c96052984f80dbdb7000000.pdf $>$. Acesso em: 23 abr. 2015. 